\title{
Torsion of Epiploic Appendagitis: Forgotten Cause of Acute Abdomen Four Cases Presentation and Literature Review
}

\author{
Abbas AR Mohamed* \\ Department of Surgical Specialties, Consultant General and Laparoscopic Surgeon, Head of the General Surgery Department, KSA
}

${ }^{*}$ Corresponding author: Abbas AR Mohamed, Department of Surgical Specialties, Consultant General and Laparoscopic Surgeon, Head of the General Surgery Department, NGH-Madinah, KSA, E-mail: abbasmoh232@gmail.com

Received: 26 Nov, 2019 | Accepted: 16 Jan, 2020 | Published: 21 Jan, 2020

Citation: Mohamed AAR (2020) Torsion of Epiploic Appendagitis: Forgotten Cause of Acute Abdomen Four Cases Presentation and Literature Review. Clin Res Open Access 6(1): dx.doi.org/10.16966/2469-6714.153

Copyright: (C) 2020 Mohamed AAR. This is an open-access article distributed under the terms of the Creative Commons Attribution License, which permits unrestricted use, distribution, and reproduction in any medium, provided the original author and source are credited.

\section{Abstract}

Epiploic appendices are fatty projections from the wall of the colon. Torsion, inflammation, and infarction of these fatty projections are a rare entity termed epiploic appendagitis. The condition is usually presented with acute abdominal pain that may be confused with many acute abdominal emergencies. We present four cases of epiploic appendagitis simulating different other causes of acute abdomen.

Keywords: Epiploic appendagitis; Appendicitis; Cholecystitis; Diverticulitis

\section{Introduction}

Torsion of epiploic appendices can present with various clinical presentations that simulate many abdominal emergencies. As the treatment of the condition is conservative, preoperative diagnosis is essential to avoid unnecessary surgical intervention with its associated morbidity and mortality. We present four cases of torsion of Epiploic appendagitis presented as acute appendicitis, acute cholecystitis, and acute diverticulitis. We also review the literature for this forgotten cause of acute abdomen.

\section{The first case}

A 36 years old male patient admitted to the surgical ward complaining of right-iliac fossa pain for two days before the admission. The pain was associated with nausea and vomiting but no other gastrointestinal symptoms. On examination, the patient was not febrile and his vital signs were normal. On examination of his abdomen, there was tenderness, rebound tenderness, and muscle guarding over the right iliac fossa. Blood tests including $\mathrm{CBC}$, Urea and Electrolytes and urine analysis were within ranges. The diagnosis of acute appendicitis was established on the clinical findings. Exploration of the abdomen done through a gridiron incision. The appendix was found to be normal. There was small necrotic mass found adjacent to the lateral wall of the caecum which seemed to be an infarcted epiploic appendage. The infarcted appendage (Figure 1) was excised after ligation of its pedicle together with the removal of the appendix. The histopathological examination of the appendix confirmed a noninflamed appendix. The patient recovered well and discharged on the third postoperative day.

\section{Second case}

The 33-years-old male admitted to the surgical ward with a complaint of right iliac fossa pain of twelve hours duration. The pain was of sudden onset and persistent, associated with burning micturition and nausea but no vomiting or other gastrointestinal symptoms. He was otherwise healthy and had no history of surgery before. He was slightly febrile and tachycardiac with a temperature of $37.8^{\circ} \mathrm{C}$ and a pulse rate of $94 /$ minute. On examination of his abdomen, there was tenderness, rebound tenderness and muscle guarding over both right iliac fossa and right lumbar region. His WBCC was $12.4 \times 109$ per L, Hemoglobin was $(12.8 \mathrm{~g} / \mathrm{dl})$, Urea and electrolytes, liver function and coagulation profile were within normal values. His urine analysis showed few pus and red blood cells. He had a CT scan abdomen which showed a well-defined fatty lesion related to the lateral wall of the ascending colon just below the liver with hype dense rim and central dot-sign (Figures $2 \mathrm{~A}$ and $2 \mathrm{~B}$ ). The diagnosis of torsion of epiploic appendicitis was established on the CT findings. The patient was treated conservatively and responds well to conservative management.

\section{Third case}

45-year- old male was admitted to our surgical ward with the right subcostal pain of one-day duration. The pain was sudden and severe initially, but it gradually eased off and became persistent. He had no vomiting or other gastrointestinal symptoms and, no urinary symptoms. He denied a history of chronic dyspepsia, fat intolerance or jaundice. His blood pressure, pulse and respiratory rate were within normal values. On abdominal examination, his abdomen was tender and rigid over the right hypochondrium with positive Murphy's sign. 
His blood test including $\mathrm{CBC}$, urea and electrolytes, liver function test and serum amylase were within the normal range. The abdominal ultrasound showed a thin-walled distended gall bladder without gallstones. It also showed a hyperechoic mass localized under the right costal margin just lateral to the right rectus muscle (Figures $3 \mathrm{~A}$ and 3B). The CT scan showed a well outlined fatty lesion associated with the proximal transverse colon with hyperdense rim and central dot-sign, associated with stranding of the surrounding fat. These features are highly suggestive epiploic appendagitis (Figure 4). The MRI showed oval shape fatty lesion with hypointense rim and a central dot of decrease signal seen in direct relation to the proximal transverse colon (Figures 5A-5B). On fat saturation images, the lesion becomes suppressed, while the peripheral rim becomes hyperintense (Figure 5C).

\section{Fourth case}

A 36-year-old male patient was admitted to the surgical ward complaining of left iliac fossa pain of three days duration. He had no vomiting, a change of bowel habits, and no history of loss of weight or rectal bleeding. On examination, the patient was not febrile with normal vital signs. Abdominal examination revealed tenderness, rebound tenderness and muscle guarding over the left iliac fossa and
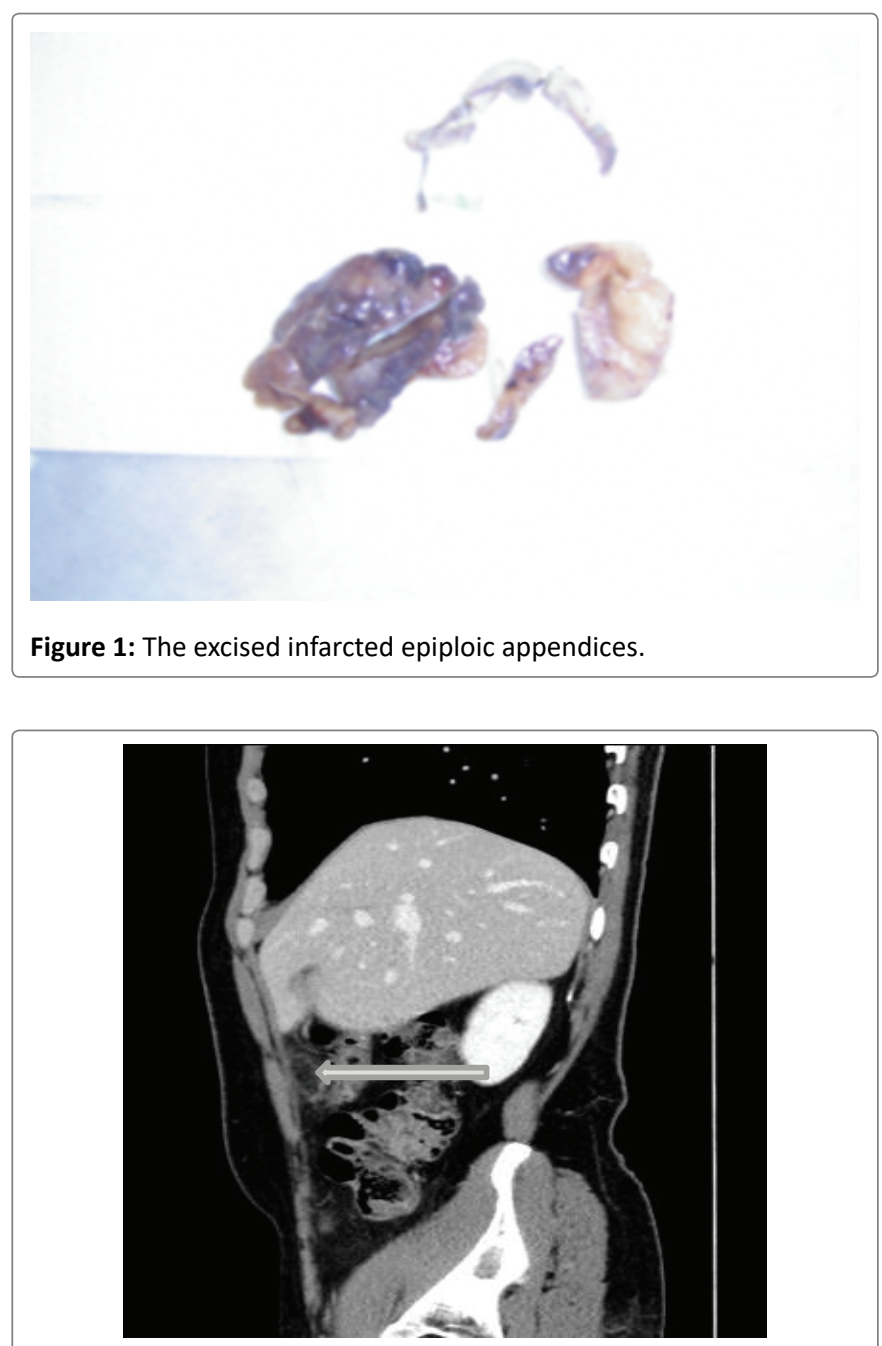

Figure 2A: The abdominal CT (sagittal view) showing a well-defined fatty lesion related to the lateral wall of the ascending colon just below the liver with hype dense rim. the left lumbar region. His blood investigations including complete blood count, urea and electrolytes, and liver function tests were within normal values apart from mild leukocytosis. The abdominal CT-scan showed a well-defined fatty lesion with hype dense rim and central dot-sign, associated with stranding of the surrounding fat, at the left iliac fossa in direct relation to the sigmoid colon (Figures 6A and 6B). The CT scan finding was classical for torsion of a sigmoid epiploic appendage (epiploic appendagitis). The CT findings were confirmed by the MRI (Figure 7A-7C). The patient was treated conservatively and he responded well to the conservative management and discharged after 5 days.

\section{Discussion}

The epiploic appendices are pedunculated sub-serosal fatty projections from the wall of the colon. They are usually arranged as

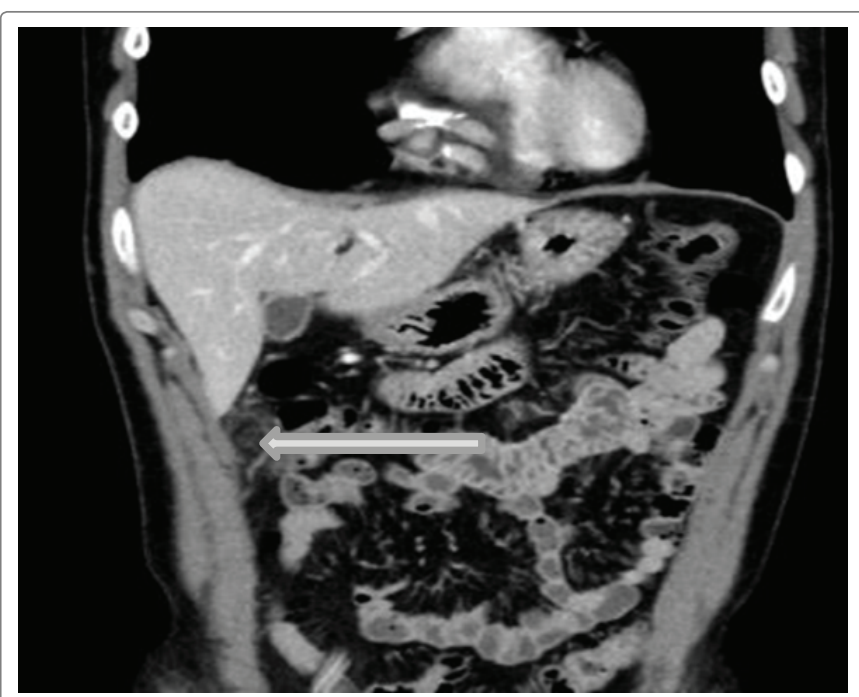

Figure 2B: The abdominal CT (coronal view) showing the same findings of figure 2 .

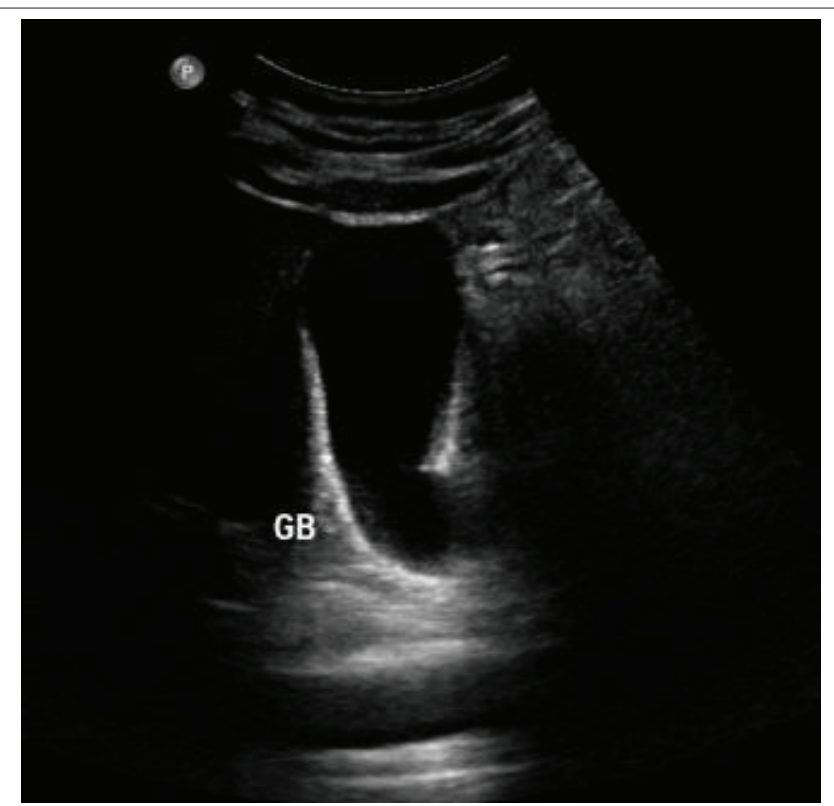

Figure 3A: The abdominal ultrasound showing a thin-walled distended gall bladder without gallstones. 


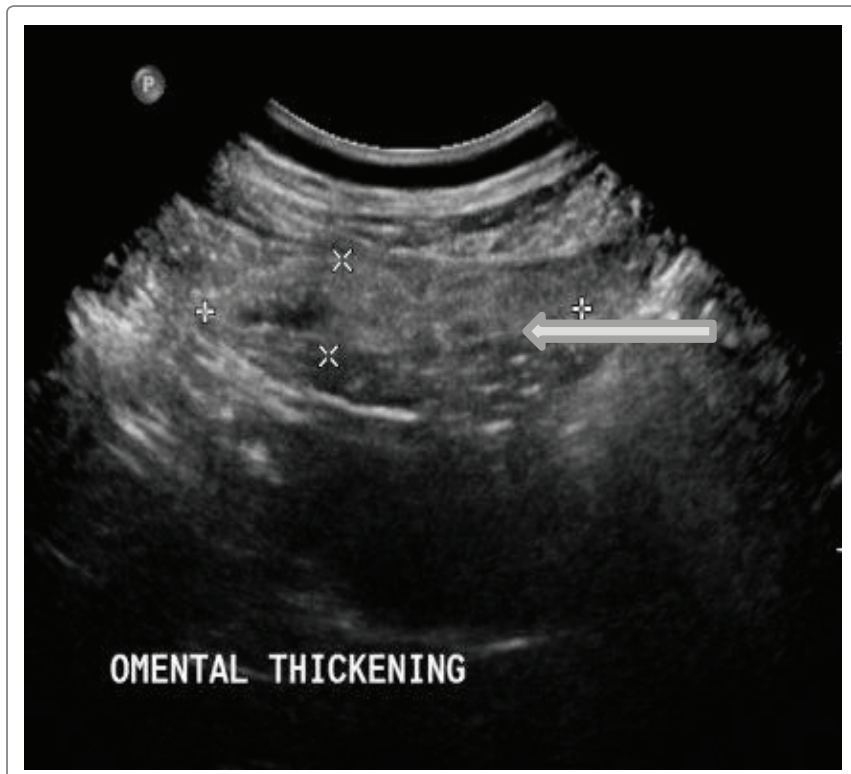

Figure 3B: The abdominal ultrasound showing a hyperechoic mass under the right costal margin just lateral to the right rectus muscle.

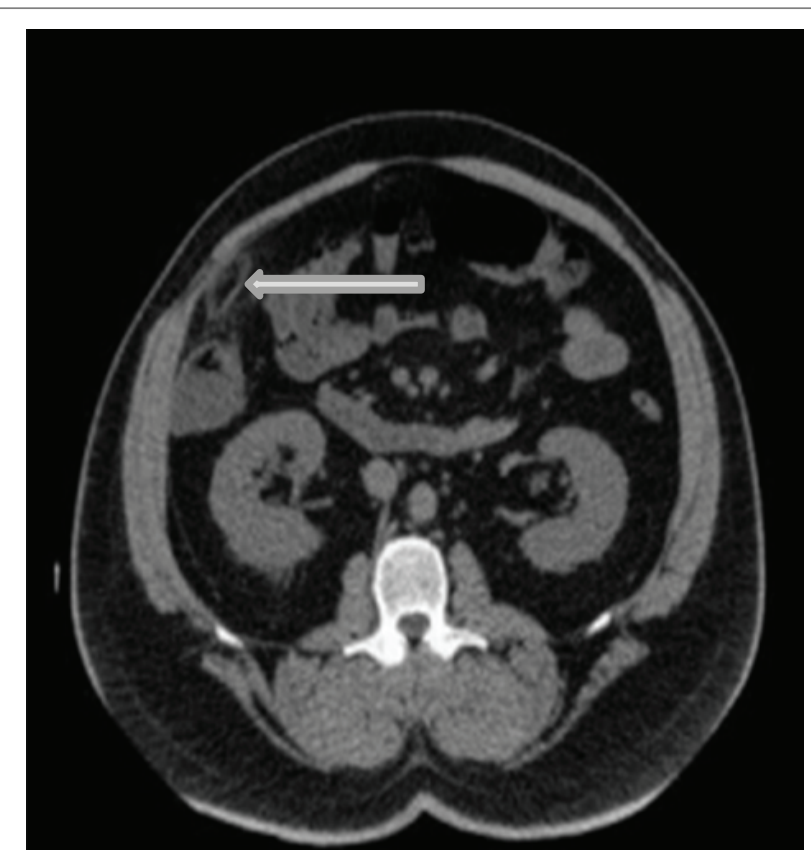

Figure 4: The abdominal CT scan showing well outlined fatty lesion in the right subcostal region in direct relation to the proximal transverse colon with hyperdense rim and central dot-sign associated with stranding of the surrounding fat.

two rows arising from the anterior and posterolateral walls of the ascending and descending colon, and one row projecting from the transverse colon. They are numerous (usually more than 100) and vary in length between 2 to $5 \mathrm{~cm}[1,2]$. Although they are distrusted all over the colon they are more numerous in the rectosigmoid junction (57\%) followed by the ileocecal region $(26 \%)[3,4]$.

The exact function of these appendages is not precisely identified. Numerous theories have been postulated, some authors suggest that they act as a protective fat pad during intestinal peristalsis, similarly

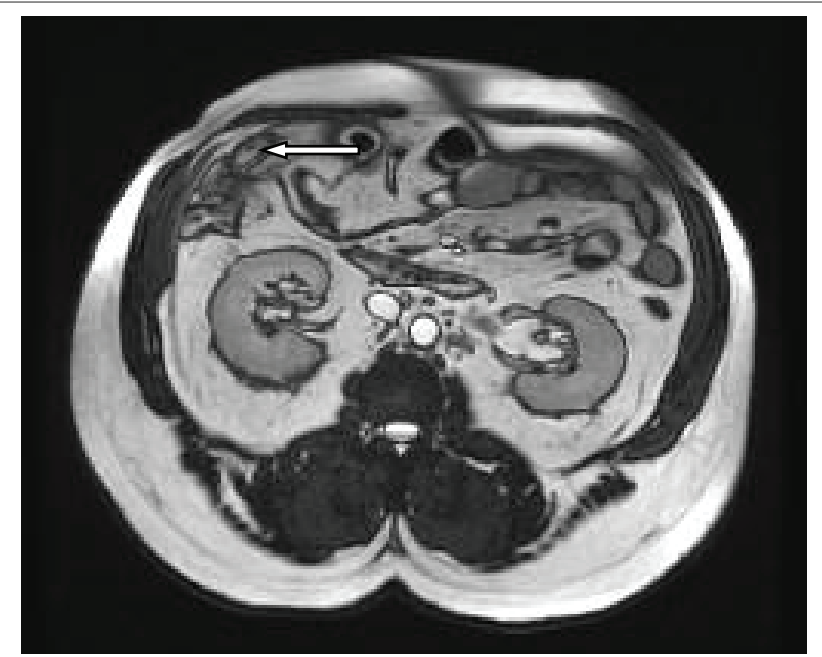

Figure 5A: T2 and T1 weighted images of the abdomen showing an oval shape fatty lesion with hypointense rim and a central dot of decrease signal seen anterior to the proximal transverse colon.

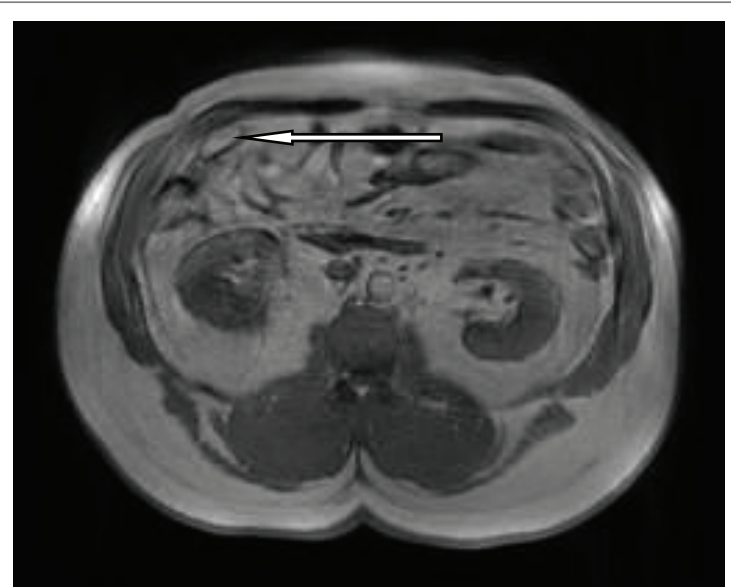

Figure 5B: T2 and T1 weighted images of the abdomen showing the same findings of figure $6 a$.

to the greater omentum. They may also play a role in fat storage and intestinal immunity $[5,6]$. Their restricted blood supply, together with their peduncle appearance, and free motility, makes them susceptible to spontaneous torsion and infarction [7].

The first case of epiploic appendagitis mimicking acute appendicitis was reported by Briggs, in 1908 [8]. Lynn et al. were the first to use the term epiploic appendagitis in the 1950s $[9,10]$ While Danielson et al. [11] were the first to describe the CT features of the condition in 1986.

The clinical presentation of the condition depends on the anatomical location of the infarcted appendices. An infarcted appendage of the caecum and the ascending colon may be confused with acute appendicitis [12], those of the sigmoid colon may be confused with acute diverticulitis [13]. The differential diagnosis of the condition extends to include many gynecological emergencies such as ruptured ectopic pregnancy, ovarian cyst rupture, and ovarian torsion [14]. Although Epiploic appendices are distributed throughout the entire colon there are only a few reported cases of torsion of epiploic appendices of the transverse colon presenting with clinical features of acute cholecystitis [15]. 


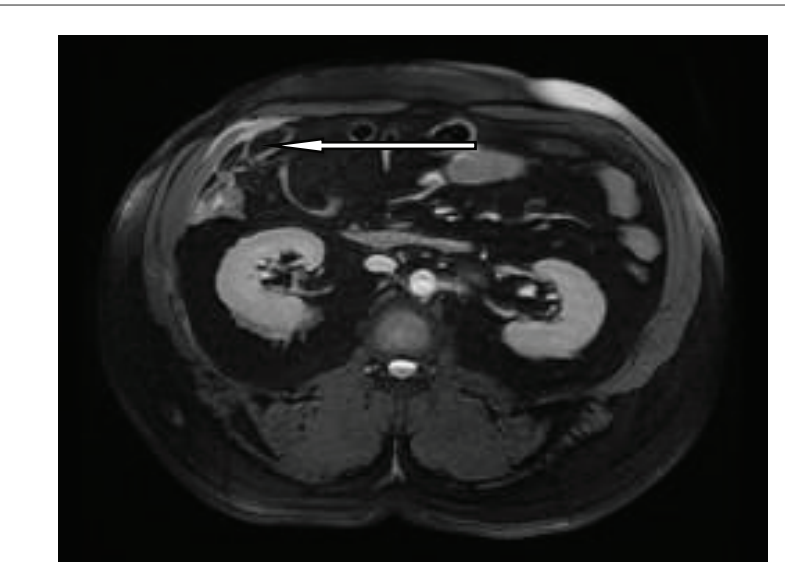

Figure 5C: T2 Fat Saturation image, the lesion becomes suppressed, while the peripheral rim becomes hyperintense.

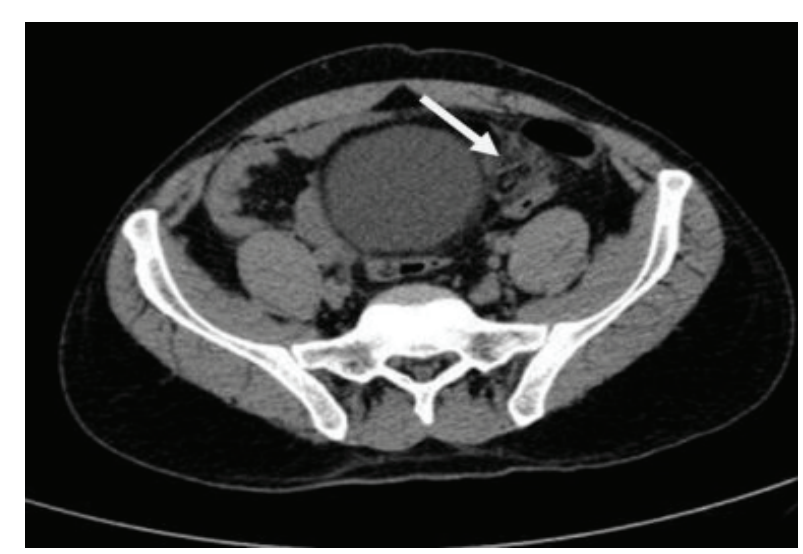

Figure 6A: The CT-scan showing well defined fatty lesion with hype dense rim and central dot-sign at the left iliac fossa in relation to the sigmoid colon wall associated with stranding of the surrounding fat.

The condition is usually more common in the females in their $2^{\text {nd }}$ to $5^{\text {th }}$ decades and also observed to be more common in obese individuals, due to larger appendices [16].

The clinical diagnosis of epiploic appendagitis depends on high awareness and early suspicion of the condition. It is always difficult to be made the diagnosis only on clinical bases due to the lack of characteristic symptoms and signs $[17,18]$. However, due to the increased use of different imaging modalities in investigating patients with acute abdomen, epiploic appendagitis is much more frequently diagnosed nowadays than before [19].

The diagnosis should be suspected in all patients with sudden onset of sharp pain localized to any part of the abdomen especially when associated with minimal gastrointestinal symptoms and normal or slightly elevated white blood count. Son HJ, et al., suggested that a localized, non-migratory pain in association with the absence of vomiting, fever or toxicity is the sine qua none of appendagitis [20].

The presentation usually involves the sudden onset of sharp localized abdominal pain which usually gets worse with cough, and pressing of the abdominal wall $[21,22]$. Although most patients with acute epiploic appendagitis usually have no disturbance of their bowel habits, few of them may complain of constipation or diarrhea [4].

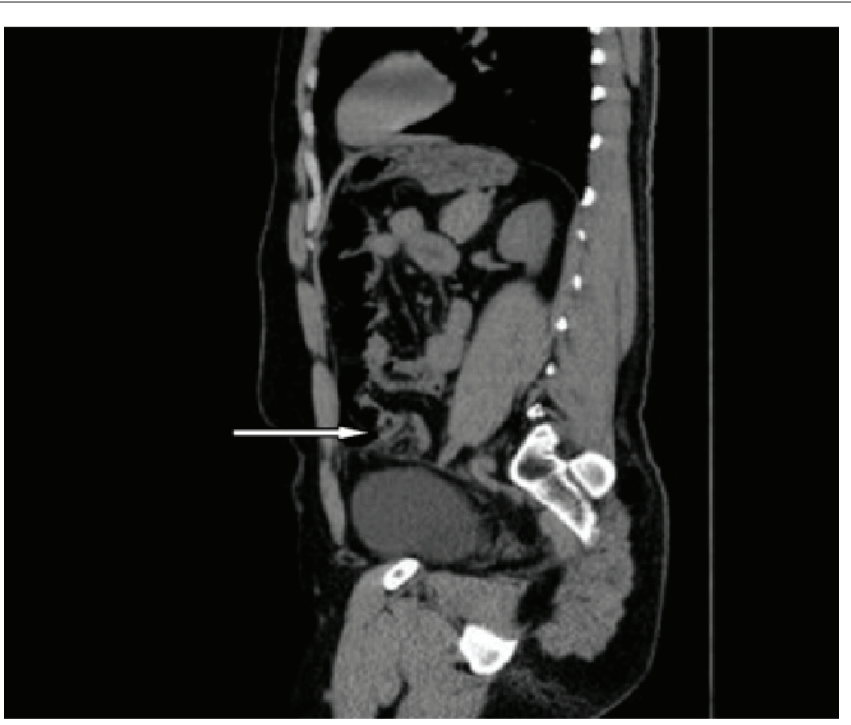

Figure 6B: The CT-scan (sagittal view) showing the same findings of figure 7 .

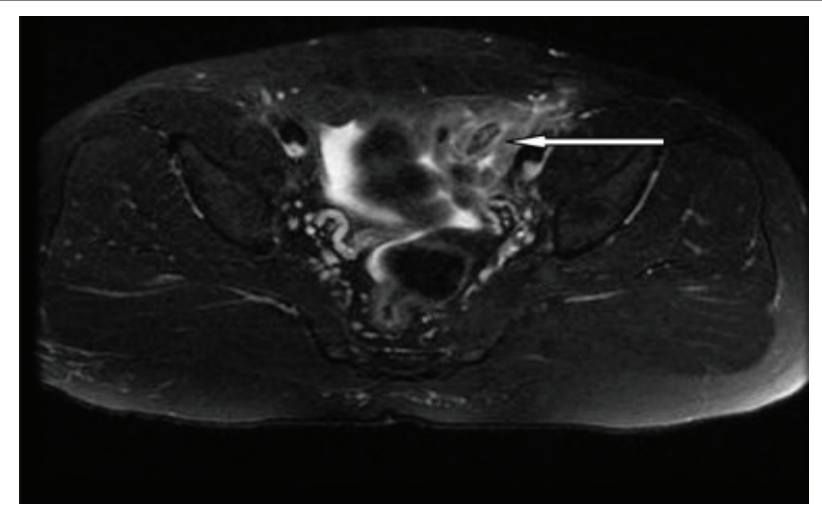

Figure 7A: MRI: showing the oval-shaped fat-suppressed signal area with a central high signal dot in the left iliac fossa in relation to the sigmoid colon.

Patients with epiploic appendagitis usually look better in the general appearance than those with appendicitis or diverticulitis of the same duration [23].

The clinical signs of the condition are the signs of localized peritonitis including localized tenderness, rebound tenderness and muscle guarding related to the anatomical site of the appendage.

Laboratory tests are also not specific for the disease and may reveal only a mild nonspecific increase in the inflammatory markers as white blood cell count and C reactive protein $[24,25]$.

Imaging modalities play an important role in the diagnosis of the condition as it is usually difficult to establish the diagnosis only based on the clinical symptoms and signs. An accurate diagnosis of epiploic appendagitis with the different available imaging modalities enables surgeons to plan for conservative management and to avoid the not required surgical intervention with its associated morbidity, mortality, and costs [26,27], (as it is evident from first, and second cases). Recognition of the radiological features of the condition enables both the radiologist and the surgeons to make the correct diagnosis. 


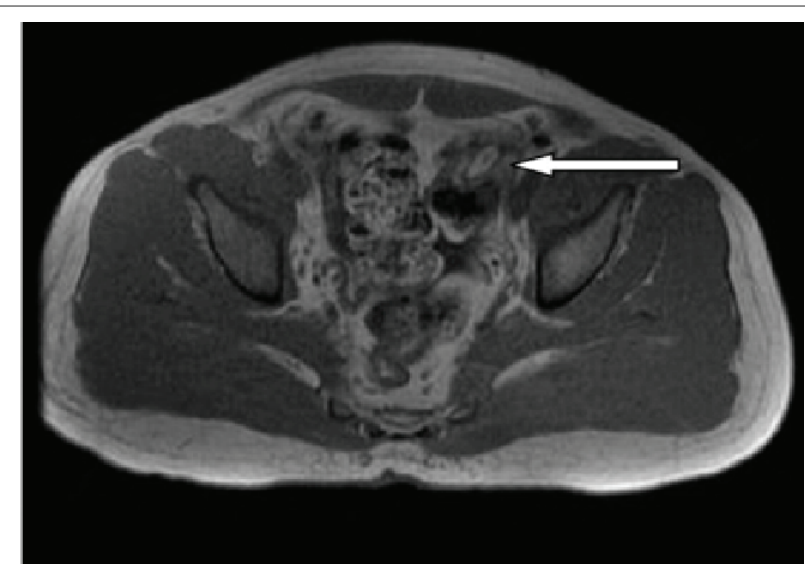

Figure 7B: Axial MRI of the pelvis showing the oval-shaped fat signal in the left iliac fossa, with a central hypodense dot.

Ultrasound being the most frequently ordered radiological investigations for patients with suspected gall bladder pathology can accurately differentiate between acute cholecystitis and epiploic appendagitis of the hepatic flexure and proximal part of the transverse colon (as in our third case). Normal epiploic appendages are not usually seen on ultrasound-unless the colon is surrounded by fluid or in presence of inflammation $[3,28,29]$. The ultrasound findings of acute appendagitis are characteristic including a hyperechoic, non-compressible, ovoid mass at the area of maximum tenderness $[3,30]$. The inflamed thickened serosa of the appendage is shown on the ultrasound as a characteristic thin hypoechoic rim surrounding the mass [30]. On color Doppler images epiploic appendagitis is characterized by the absence of flow, in contrast to the high flow detected in acute diverticulitis [31-33].

CT scan is the gold standard modality for the diagnosis of epiploic appendagitis [34]. Epiploic appendagitis appears on CT scan as ovoid mass surrounded by a hyperdense rim. This rim is diagnostic for the epiploic appendagitis which refers to as hyperattenuating ring sign. The hyperdense rim represents the inflamed peritoneal covering of the epiploic appendage. Others' CT scan feature of epiploic appendagitis is the central dot which is a hyperattenuating area at the center of the mass and a longitudinal linear area corresponding to the thrombosed artery of an appendage or central areas of hemorrhage [6]. The last two features are helpful in the diagnosis, but their absence does not exclude the diagnosis of acute epiploic appendicitis $[6,35,36]$. Usually, the CT findings of the condition could persist for six months, although the symptoms and signs are usually resolved in two weeks in most patients [29].

Although MRI is not frequently performed for the diagnosis of epiploic appendicitis, MRI features are also characteristic [16]. Epiploic appendagitis appears on magnetic resonance $\mathrm{T} 1$ and $\mathrm{T} 2$ weighted images as ovoid fat intensity with a central dot with enhancing rim with gadolinium [37].

The increasing use of laparoscopy nowadays for patients with suspected appendicitis has helped in diagnosing the condition reducing the morbidity and mortality of laparotomy in those patients [25]. However, some authors advocate laparoscopic management rather than conservative management of the condition even if the diagnosis was made preoperatively to avoid possible complications of conservative management $[38,39]$.

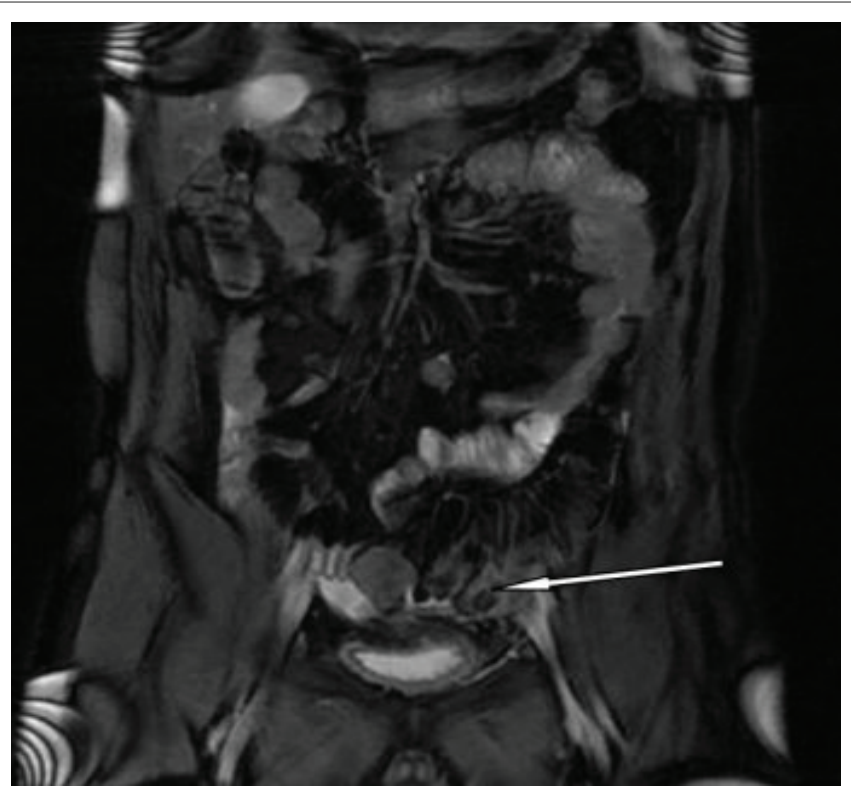

Figure 7C: Coronal fat sat image showing the lesion with the nonsuppressed surrounding inflamed fat at the left iliac fossa.

\section{Summary}

Torsion of epiploic appendices is a rare disease entity. Depending on its location, epiploic appendagitis may be confused with many acute abdominal emergencies. Surgeons should be aware of the condition and consider it in the differential diagnosis of acute abdomen. The clinical presentation of the condition depends on the location of the infarcted appendices. An infarcted appendage of the caecum and the ascending colon may mimic acute appendicitis, those of the sigmoid colon may mimic acute diverticulitis. Recognition of the radiological features of the condition enables the radiologist to make the correct diagnosis and surgeons to make the right decisions. As the condition is self-limiting preoperative diagnosis is important to decrease morbidity and mortality associated with unjustified invasive surgical interventions with its associated morbidity and prolonged hospitalization with its associated cost.

\section{Conflict of Interest}

None declared.

\section{References}

1. Mohamed AA, Shareefi O, Hussin KM, Alnehmi FS (2014) Epiploic Appendagitis: CT and MRI Features: Case Presentation. The Internet Journal of Surgery 31: 1-7.

2. Montgomery KN, Doherty MC, University of Mississippi Medical Center, Jackson (2013) Primary epiploic appendagitis. Appl Radiol 42: 17-18.

3. Rioux M, Langis $P$ (1994) Primary epiploic appendagitis: clinical, US, and CT findings in 14 cases. Radiology 191: 523-526.

4. Thomas JH, Rosato FE, Patterson LT (1974) Epiploic appendagitis. Surg Gynecol Obstet 138: 23-25.

5. Marinis TP, Cheek JH (1949) Primary inflammation of the Appendices Epiploicae-with review of the literature and report of six additional cases. Ann surg 129: 533-537. 
6. Ghahremani GG, White EM, Hoff FL, Gore RM, Miller JW, et al. (1992) Appendices epiploicae of the colon: radiologic and pathologic features. Radiographics 12: 59-77.

7. Pereira JM, Sirlin CB, Pinto PS, Brooke JR, Damien SL, et al. (2004) Disproportionate fat stranding: a helpful CT sign in patients with acute abdominal pain. Radiographics 24: 703-715.

8. Briggs WA (1908) Torsion of appendices epiploicae and its consequences. Am J Med Sci 135: 864-870.

9. Bunni J, Corrigan A, Jacob K, Schuijtvlot M (2010) Epiploic appendagitis: a case report highlighting correlation between clinica features, computed tomography images and laparoscopic findings. Int J Surg 8: 401-403.

10. Dockerty MB, Lynn TE, Waugh JM (1956) A clinicopathologic study of the epiploic appendages. Surg Gynecol Obstet 103: 423-433.

11. Danielson K, Chernin MM, Amberg JR, Goff S, Durham JR (1986) Epiploic appendicitis: CT characteristics. J Comput Assist Tomogr 10: $142-143$

12. Lee YC, Wang HP, Huang SP, Chen YF, Wu MS, et al. (2001) Gray-scale and color Doppler sonographic diagnosis of epiploic appendagitis. J Clin Ultrasound 29: 197-199.

13. Issa IA, Berjaoui MT, Hamdan WS (2010) Primary epiploic appendagitis: from A to Z. Int Med Case Rep J 3: 67-69.

14. Sorser SA, Maas LC, Yousif E, Maas L (2009) Epiploic appendagitis: the great mimicker. South Med J 102: 1214-1217.

15. Lien WC, Lai TI, Lin GS, Wang HP, Chen WJ, et al. (2004) Epiploic appendagitis mimicking acute cholecystitis. Am J Emerg Med 22 507-508.

16. Almeida AT, Melão L, Viamonte B, Cunha R, Pereira JM (2009) Epiploic appendagitis: an entity frequently unknown to clinicians-diagnostic imaging, pitfalls, and look-alikes. AJR Am J Roentgenol 193: $1243-1251$

17. Brady SC, Kliman MR (1979) Torsion of the greater omentum or appendices epiploicae. Can J Surg 22: 79-82.

18. A Mohamed, M Abukhater (2007) Primary Epiploic Appendagitis: A Rare Cause of Acute Abdomen. The Internet Journal of Surgery 17.

19. Van Breda Vriesman AC, de Mol van Otterloo JC, Pulaert JB (2003) [Epiploic appendagitis: an underestimated self-limiting acute abdominal condition]. Ned Tijdschr Geneeskd 147: 1113-1118.

20. Son HJ, Lee SJ, Lee JH, Kim JS, Kim YH, et al. (2002) Clinical diagnosis of primary epiploic appendagitis: differentiation from acute diverticulitis. J Clin Gastroenterol 34: 435-438.

21. Singh AK, Gervais DA, Hahn PF, Rhea J, Mueller PR (2004) CT appearance of acute appendagitis. Am J Roentgenol 183: 1303-1307.

22. Baker ME (2008) Imaging and interventional techniques in acute left-sided diverticulitis. J Gastrointest Surg 12: 1314-1317.
23. Sirvanci M, Balci NC, Karaman K, Duran C, Karakas E (2002) Primary epiploic appendagitis: MRI findings. Magn Reson Imaging 20: 137-139.

24. Aronsky D, Z'graggen K, Banz M, Klaiber C (1997) Abdominal fat tissue necrosis as a cause of acute abdominal pain. Surgical endoscopy 11: 737-740.

25. Mazza D, Fabiani P, Casaccia M, Baldini E, Gugenheim J, et al. (1997) A rare laparoscopic diagnosis in acute abdominal pain: torsion of epiploic appendix. Surg Laparosc Endosc 7: 456-458.

26. Schnedl WJ, Krause R, Tafeit E, Tillich M, Lipp RW, et al. (2011) Insights into epiploic appendagitis. Nat Rev Gastroenterol Hepatol 8: 45-49.

27. McClure MJ, Khalili K, Sarrazin J, Hanbidge A (2001) Radiologica features of epiploic appendagitis and segmental omental infarction. Clin Radiol 56: 819-827.

28. Sand M, Gelos M, Bechara FG, Sand D, Wiese TH, et al. (2007) Epiploic appendagitis--clinical characteristics of an uncommon surgical diagnosis. BMC Surg 7: 11 .

29. Singh AK, Gervais DA, Hahn PF, Sagar P, Mueller PR, et al. (2005) Acute Epiploic Appendagitis and Its Mimics. Radiographics 25: 15211534.

30. Webb EM, Green GE, Scoutt LM (2004) Adnexal mass with pelvic pain. Radiol Clin North Am 42: 329-348.

31. Carmichael DH, Organ CH (1985) Epiploic disorders: Conditions of the epiploic appendages. Arch Surg 120: 1167-1172.

32. Danse EM, Van Beers BE, Baudrez V, Pauls C, Baudrez Y, et al. (2001) Epiploic appendagitis: color Doppler sonographic findings. Eur Radiol 11: 183-186.

33. Mollà E, Ripollés T, Martínez MJ, Morote V, Roselló-Sastre E (1998) Primary epiploic appendagitis: US and CT findings. Eur Radiol 8: 435 438.

34. Gurses B, Ekci B, Akansel S, Kabakci N, KucukS, et al. (2007) Primary epiploic appendagitis: the role of computed tomography in diagnosis. Australas Radiol B155-B157.

35. Jain TP, Shah T, Juneja S, Tambi RL (2008) Case of the season: primary epiploic appendagitis: radiological diagnosis can avoid surgery. Semin Roentgenol 43: 4-6.

36. Ozkurt H, Karatag O, Karaarslan E, Rozanes I, Basak M, et al. (2007) CT findings in epiploic appendagitis. Surgery 141: 530-532.

37. Christianakis E, Paschalidis N, Filippou G, Smailis D, Chorti M, et al. (2009) Cecalepiploica appendix torsion in a female child mimicking acute appendicitis: a case report. Cases J 2: 8023.

38. Diaco JF, Diaco DS, Brannan AN (1993) Endoscopic removal of an infarcted appendix epiploica. J Laparoendosc Surg 3: 149-151.

39. Vazquez-Frias JA, Castañeda P, Valencia S, Cueto J (2000) Laparoscopic diagnosis and treatment of an acute epiploic appendagitis with torsion and necrosis causing an acute abdomen. JSLS 4: 247-250. 